This item is the archived peer-reviewed author-version of:

Rape without bodies? Reimagining the phenomenon we call "rape"

\title{
Reference:
}

Porter Holly.- Rape w ithout bodies? Reimagining the phenomenon we call "rape"

Social politics : international studies in gender, state, and society - ISSN 1072-4745 - 25:4(2018), p. 589-612

Full text (Publisher's DOI): https://doi.org/10.1093/SP/JXY029

To cite this reference: https://hdl.handle.net/10067/1565790151162165141 


\section{Rape Without Bodies? Reimagining the phenomenon we call "rape"}

Holly Porter

"How do you define rape?" When one does research on rape, this question, is one of the most basic and common. It is also one of the first things which a researcher working on the topic might outline while planning fieldwork or designing tools for data collection and analysis. Ostensibly, the question is about methodology. But if we scratch beneath the surface, there is a deeper question which underlies it, one of enormous import: What is rape? What are we actually talking about when we talk about rape? Is it a socio-cultural or legal construct? Is it a bodily experience? Is it an objective thing existing apart from subjective human experience — something which transcends the individual and the cultural? This line of questioning goes beyond the scholarly need to outline scopes of inquiry, beyond methodology sections which define terms used in studies - it is fundamentally an ontological question. In other words, it is a question of what is. What makes us say that this is rape and that is not? If rape is a kind of category for reality what does it contain and how do we know?

This ontological question is the foundation (or perhaps better put the undercurrent) of all methodology on the topic, and ways of going about knowing about it. We begin with some preconceptions about what it is. We might even assume that there is quite significant shared understanding of what it means to talk about rape. We might consider the phenomenon of "rape" as both a concept and as an experience, keeping in mind that these are not the same thing and yet they give shape to each other. At times the concept of "rape" seems to float with weak tether to the people who experience it. In terms of the concept, rape is often understood as a sexual experience existing somewhere along a continuum of personal agency on the one hand and force or coercion on the other. In terms of its wrongness and its illegality 
at different places and at different times, a line is drawn somewhere along the continuum separating acceptable and transgressive sex. But where does this threshold come from?

The rest of this article explores these questions from different angles. First, how the concept, of rape is legally constructed and comprises different movements in legal approaches toward and away from the particular body to the social body. Second, I explore socio-cultural constructions of abhorrent sexuality, concepts and experiences of forced sex-whether or not it is also conceptualized by the woman who experiences it as "rape". Third, I reflect on the possibilities of the body as a starting point for analysis and the ways it is materially dividual and or individual. Fourth, we explore the implications of some startlingly decentering ethnographic material: rape without bodies — rape by spirits — and consider what this might mean for our understanding of the phenomenon of rape. Far from a peripheral experience, if we are willing to seriously think about non-corporeal rape it challenges two commonly held truisms: the reality and privilege of the individual; and the reality and privilege of the material. This gives rise to methodological concerns particularly when engaging with research of the type and nature that involves the active breaching of one or both of these concerns.

Finally, I suggest a reimagining of rape to bring the concepts and experiences considered in the article together. The threshold in question, I will argue, which separates sex that is acceptable from sex that is rape, is existential and phenomenological. That is, the source of violation is a deeply existential one. It cannot be reduced to any one thing, legally or socially patterned, or universally shared sense of material biological violation. Rather, I argue for a reimagining of rape as a sexual transgression of a person's being. 


\section{Some orientations}

Issues of sexual violence have been the focal point of my scholarly work for the past 10 years. Largely, this has been ethnographic research in northern Uganda amongst the Acholi people. My reflections here are premised on the idea that the lived experiences of my informants are not just examples for arguments, rather they constitute theory and this may have wider implications - that the experiences of Acholi women have something to contribute to broader discussions of sexual violence and our understanding of what rape is.

Originally, I chose rape as a focus of inquiry because I was interested in responses to crime and wrongdoing in the aftermath of war. I thought that a useful way of exploring this would be to look in-depth at a particular crime. Much analysis and theorizing concerning wars and civil wars focuses on data related to the number of deaths. Nordstrom, provocatively, suggests that this is no theory at all, since it is based on data, which systematically delete, or at least underrepresent, girls and women (Nordstrom 2005). I chose rape, partly, because I wanted to add a corrective voice to overemphasis on approaches to understandings of civil war based on (often) numeric data on killing. But a principal rationale for focusing on rape, was because I understood it as an embodied experience, and the bodies are alive and can be interacted with. ${ }^{i}$ Methodologically, rape provides insight into a corporeal experience of violence in a way that killing cannot. I understood rape as an embodied experience that can be reflected upon and shared with others subsequent to the event. I also wanted the starting point for exploring rape to be as it was experienced, rather than beginning from a more sociocultural concept (in my case a western feminist concept) or legal concept which might be (and at times is) abstracted from the bodies that experience it. 
The context for this exploration was northern Uganda, where I had first spent 3 years as an aid worker beginning in 2005 before the war in Uganda effectually ended. Notions of what rape is and what constituted sexual transgression were far from straightforward. I recall a sexual and gender-based violence training session for a youth group facilitated by an officer from the United Nations Office for the High Commission on Human Rights. Typical of many such trainings around the world utilizing a feminist perspective, it conveyed the idea that rape is not about sex, it is about violence (McPhail 2015). At one point, the facilitator wrote a definition of consent on a flip-chart for the Acholi participants. Consent, she wrote, was an agreement between parties with equal power. She went on to say that sex without consent was rape. By this definition most of the sex in Acholi [if not the world] would be classified as rape. Indeed, such a position echoes feminist schools of thought where the inferior status of women with regard to sexual freedom in patriarchal social structures make impossible the true exercise of feminine sexual agency. ${ }^{\text {ii }}$ Some of the elderly women in my study found the idea that they could have or would have been raped by their husbands absurd. For some of them, the idea that they had any right over their own sexuality had not occurred to them and they had not considered the possibility of refusing. Yet such an understanding of consent and rape was far from the concepts of my informants. It raises the question of how tenable a concept of rape (or consent) is without one of sexual autonomy. There is an evident tension between the individual and the societal to determine what constitutes sexual wrongdoing.

At the beginning of my scholarly exploration into these questions in 2008 I tried to avoid choosing a threshold for sexual wrongdoing which was externally derived. I examined broader notions of sexual mores and transgressions (which includes many mutually-desired sexual acts), but I also wanted to know about forced sex-whether it was considered wrongdoing or not. I tried to stay as faithful as possible to women's understandings of their 
own experiences of sex that is forced or which they did not agree to. Such an approach built on established feminist practice of privileging a woman's own account of the sexual violence she has experienced, and was also meant to avoid (as much as it is possible to do so) imposing an external legalistic or western liberal normative definition of rape (Hawkesworth 1989). A key consideration, was then whether women were aggrieved by a forceful sexual encounter. In Acholi, people often articulate being aggrieved as something that made their heart "leak" or cwinyé cweer, which Crazzolara defines as: offended, afflicted, sorrowful (Crazzolara 1938: 238). What this meant is that in the quantified prevalence of my study, I did not "count" as "rape" sexual experiences if the woman in question was not aggrieved by the act. In other instances when the woman was aggrieved, even if she may not have used the word "rape" to describe what happened to her, these were counted when she talked about force, her lack of desire, the feeling that the man had either known and overpowered her or had not paid attention to her will in the situation. There is a kind of tension in this approach, because while avoiding an externally imposed definition, it still references an object—or to use Merleau Ponty's formulation, by turning my attention in this way an object is constituted out of an "indeterminate horizon." While aware of this tension, there was a need to begin somewhere. As it happens, that same tension appears evident in the ethnographic data elaborated below.

Where then, does the threshold which separates sex that is okay from sex that is rape come from? Is it simply the way that bodies are made-biologically and inalienable and/or also constructed? Does it come from a deeply embodied sense of being violated or a normative limit that is also a social and or legal construct? In my research, I encountered Acholi women who described the rather quotidian experience of being forced to have sex, where rape never ceased to be experienced as violation. They would say being forced to have sex is something 
that "happens" (time,), implying a level of normalcy but it still aggrieved them-or to use the Acholi idiom, it made their hearts leak. Such experiences suggest the limits of routinization of violation. They can affect the social and structural ways violence is experienced, but somewhere, on the body, I reasoned, there is a threshold and perhaps universal story of the badness of being forced — even if and when there is no readily applicable legal concept.

A subtext to this is the idea of the body as central to understanding rape. But how important is it? Is the individual body an essential part of the experience and the concept of rape? Is it/should it be the transgression of an internal threshold of violation that a person experiences? Or something which is not just down to the subjectivity of a person? Is it a thing which transcends the individual and the cultural? In the following sections, I explore these questions from different angles as outlined above: legal constructions, socio-cultural understandings, the body, and lastly the non-corporeal.

\section{The legal construction of rape}

"Each time a rape law is created or applied," as MacKinnon put it, "or a rape case is tried, communities rethink what rape is" (MacKinnon 2005). I would say, it invites us to rethink what rape is, perhaps reflects (however imperfectly) what it is and (to some extent) shapes what it is. Inasmuch as the law has a mutually constitutive relationship with the concepts and experiences of the people it governs it is important to our discussion of the threshold which distinguishes rape from other sexual activity. Below we consider different movements in legal approaches toward and away from the particular body to the social body in delineating rape. Legal definitions vary, and all such definitions are in turn open to differing interpretations and use. Feminist, anti-rape scholarship and activism in the past decades have 
concentrated on easing the path of prosecuting rape, pushing for reform of legal definitions of rape, and improving processes from policing to prosecution. In the context of war and political struggle, definitions of rape have recognized the ways sexual violence can be used as a weapon in war, as a crime against humanity, as torture, and as genocide. The concept of rape has also vacillated between a more singular focus on individual consent to foregrounding coercive circumstances in determining legality of sexual experiences (MacKinnon 2005; Munro 2010). These often mirror the shifting emphases in understanding sexual wrongdoing as a social crime against mutually constitutive beings or against autonomous and independent individuals whose rights have been violated. Below I will elaborate some of these legal movements both internationally and in the domestic legislation of my own research context, Uganda. I do so, it should be noted, as an anthropologist, and not a legal expert. From this "outside" perspective, I will bring the legal movements into conversation with our ontological questions about what rape is.

Much of the law (including international human rights law, international humanitarian law, international criminal law, and domestic law) pertaining to rape tends to frame it as one of two things: either it is a crime against an individual woman, or it is a crime against a wider social body and moral order. Feminists' legal activism holds in tension sometimes competing goals - on the one hand to have rape recognized as a crime of severe gravitas, e.g. that it is so awful as to be tantamount to genocide, a crime against humanity, and torture. On the other hand, to have rape recognized as awful in its own right and argue it should not need to be the predicate of a crime that touches the social body to be prosecuted. A related question is whether rape perpetrated in war should be linked to war or not. If violence in war, as is well noted by gender scholars, is a continuum of violence against women (Boesten 2014; Sylvester 2013), then one could object to prosecution of rape that is based on a false 
distinction between war and peace time. In relation to criminal proceedings, there is a simultaneous drive to push rape and other sexual crimes up the hierarchy of crimes. Should rape be defined as a stand-alone crime, not as a crime subsumed within another - e.g., a crime against humanity or a war crime - and hence tied to systematic societal violence and political action? Thus much attention in feminist legal scholarship and activism has been around how rape is classified. Underlying these debates we can see the fundamental tension between the primacy of the individual and whether people are fundamentally relational.

The language used in legal instruments reflects this tension. The Geneva Conventions stipulate that women should be protected during war against "attacks on their honor", a framing which essentially removes the political content of the crime (Chinkin 1994). After World War II, the International Military Tribunal Charter at Nuremburg recognized rape as a crime but because of reluctance to call attention to rape committed by Allied forces no one was prosecuted (Goldstone 2002). A quarter-century later, the feminist movement of the 1970s reinvigorated an interest in rape in war. However, as recently as the Truth and Reconciliation Commission in South Africa in the 1990s, amnesty applications for rape were rejected because they were deemed not to meet the criteria of politically motivated crime (Moffett 2006; Moon 2006). During the same period, a focus within academia, by policy makers and by the media on sexual violence in war was galvanized by the events of the Rwandan genocide and the breakup of the former Yugoslavia. The ad hoc tribunals established in both cases recognized rape for the first time as torture, a crime against humanity, and a war crime (Skelsbaek 2001; Snyder et al. 2006). A watershed in jurisprudence for sexual crime was the conviction in 1998 of Akayesu for crimes committed during the Rwandan genocide that included rape and other sexual crimes. In this decision the International Criminal Tribunal for Rwanda defined rape as: 
a physical invasion of a sexual nature, committed on a person under circumstances which are coercive. The Tribunal considers sexual violence, which includes rape, as any act of a sexual nature which is committed on a person under circumstances which are coercive. (Akayesu decision, para 688)

The wording of the decision used victim-centered language and emphasized the element of coercion. MacKinnon stated that, "for the first time, rape was defined in law as what it is in life" (MacKinnon 1994). Perhaps, she might argue, the legal concept of rape was moving closer to the experience. Such developments have influenced perceptions of rape as a crime of severe gravitas, have increased penalties for perpetrators of rape and decreased ways in which trials and legal processes have often been prejudicial to women who were raped. But the implications of achievements in the ad hoc tribunals for broader feminist projects are contested. Charlesworth, for instance, criticized the Akayesu decision for being tethered to "widespread and systematic" attacks where rape is violating international humanitarian law. She critically pointed out that rape in the ICTY was engaged because it was an aspect of the destruction of a community. In the tribunals, she argued, "[R]ape is wrong, not because it is a crime of violence against women and a manifestation of male dominance but because it is an assault on a community defined only by its racial, religious, national or ethnic composition. In this account, the violation of a woman's body is secondary to the humiliation of the group." She continued that, "rape and sexual assault should be analysed in international law as crimes against women, rather than offenses against their communities" (Charlesworth 1999: 387 emphasis mine). A result of the prosecutions and evolving legal instruments was that, arguably, a problematic hierarchy of sexual violence was developing and victim experiences further marginalized (Henry 2014). As Copelon put it, the "consequence of defining certain rapes as public in international law is to make private rapes seem somehow 
less serious" (Copelon 1994: 389). What rape was, for international law, or for "humanity" was narrowing.

The International Criminal Court's Rome Statute built on the jurisprudence of the ad hoc tribunals and added some specificity to the definition of rape, using the language "of invasion of the body of the victim, force and coercive environment" (Rome Statute, Arts 2, 7(1)(f), $7(1)(\mathrm{g})$, and 7(2)). Here, we might note the appearance in the statute of an idea of the individual bodily aspect of the crime as well as the coercive circumstances.

But the way that rape was classified in the Rome Statute left many unsatisfied (Halley 2008a, 2008b). Charlesworth and Chinkin argued that prosecutors should avoid charging rape as a crime "against humanity" and instead should try it as a grave breach in its own right. Subsuming rape within crimes against humanity, they argue, implies that the harm inflicted is against humanity where charging it as a grave breach could individualize harm which allows the gendered aspect to come into focus (Charlesworth and Chinkin 2000). As Bedont put it, classifying sexual violence under other crimes, "hides the sexual aspect of the crime and denies the particular harm suffered by a victim of rape" (Bedont 1999: 196-97 emphasis mine). Similarly, Lehr-Lehnardt argues for how listing rape as a grave breach would reinforce, "the notion that the injury was suffered by the individual instead of by society, or even more generally by humanity.” (Lehr-Lehnardt 2002: 341)

If we bring this discussion back to our question of what rape is, legal scholars seem divided on whether or not rape is or should be a crime against an individual woman or whether it is against a larger social body — and whether the social body in question is women more broadly or a socio-cultural community. 
In the context of my research, in Uganda, interestingly, the law against rape is contained in the section of the Penal Code on crimes against morality, in contrast to most western countries where it now falls under the category of violent crimes. ${ }^{\text {ii }}$ One reading of this is that classifying rape as against morality makes it a crime that is less about individual women and more about societal mores (Uganda Penal Code Act, CAP 106, (1998), Chapter XIV, sec.

123.) The Ugandan Penal Code defines rape as:

Any person who has unlawful carnal knowledge of a woman or girl, without her consent, or with her consent, if the consent is obtained by force or by means of threats or intimidation of any kind or by fear of bodily harm, or by means of false representations as to the nature of the act, or in the case of a married woman, by impersonating her husband, commits the felony termed rape..$^{\text {iv }}$

The inclusion of the word "unlawful" to qualify the lack of consent implicitly suggests that there might be a lawful way of gaining "carnal knowledge" of a woman or girl without her consent. It leaves open an ambiguity, for example, about marital rape which has, to my knowledge, never been prosecuted in Uganda. In Uganda, a more often prosecuted legal prohibition against forced sex, also in the Penal Code's crimes against morality section, is called "defilement" or "aggravated defilement" (which in most western contexts would typically be called "statutory rape"). In the Penal Code, defilement is defined as when: "Any person unlawfully has sexual intercourse with a girl under the age of eighteen years" (Uganda Penal Code Act, CAP 106, (1998), Chapter XIV, sec. 129, emphasis mine). According to Ugandan law, a person convicted of rape or defilement is liable to the death penalty. 
In 2007 the Penal Code was revised to divide defilement into two categories, "simple" and "aggravated." According to the act, "aggravated defilement" refers to cases where: "The victim is aged below 14 years, where the offender is infected with HIV, where the offender is a parent, guardian or person in authority over the victim, where the victim is a disabled person or where the offender is a serial offender." Such cases can only be tried by the High Court, and the death penalty may apply (Penal Code Amendment Act, 2007).

The language of the division of "simple" and "aggravated" seems to recognize the importance of relations of unequal power in sexual experiences. Additional physical violence and a consideration of consent of the individual are absent. In practice however, cases are routinely divided by the girl's age alone while the other factors are effectively ignored. ${ }^{\mathrm{v}}$ This is perhaps not surprising. The law is applied in reference to broader social understandings of sexual wrongdoing, and sex with a girl without developed breasts is widely condemned as unnatural and heinous. If a girl between 14 and 18 is raped, even under circumstances that would have fallen into the aggravated criteria, it is considered "simple" defilement, with a maximum sentence of life imprisonment - and often a fine and much shorter time in prison and can be handled by Chief Magistrates or the Children and Family Court. ${ }^{\mathrm{vi}}$

Individual consent and whether or not it has been given in a sexual encounter has long been a hallmark of rape definitions. In some jurisdictions this is paired with the use of force and/or coercive circumstances--the merits and implications of the varied approaches are the subject of some feminist disagreement. MacKinnon points out that consent views rape as fundamentally a deprivation of sexual freedom, "a denial of individual self-acting" and turns on individuals' states of mind (the victim's and the perpetrator's). Coercive circumstances, in contrast sees rape as a crime of inequality and turns on the context and exploitation of a 
relative position (MacKinnon, 2005). A crucial and debated question, also reflected in international and domestic legislations regarding rape discussed above- -is what to do in circumstances where consent may be irrelevant, that is, where the choices of the alleged victim are profoundly limited to the point where "true" agency cannot be assumed. Some schools of thought would hold that patriarchal power is already totalizing enough in peacetime to warrant a turn from consent to coercion. But they are perhaps no more apparent than in the extreme contexts presented by war, where abduction, weapons, immense vulnerability, or poverty characterize the parameters within which people act and are acted upon. Most of my research has occurred in just such a setting, northern Uganda. In the context of war, there was early traction for the idea that coercive circumstances negated the validity of consent, and thus if the circumstances were established it would not be necessary to show either directly applied force or lack of consent (Halley 2008a). This position has been both strongly supported and contested in the literature. Some recent case law in the ICTY and ICC has seen consent re-emphasized (Halley 2008b; Munro 2010). To greater or lesser degrees, consent is always qualified, and in most instances of sex with the opposite sex unequal gender dynamics are present. ${ }^{\text {vii }}$ To deal with this recognition of circumscribed agency, there have been legal attempts to add qualifying words to consent: enthusiastic, positive, chosen, autonomous, conscious, affirmative, informed, or freely given (Schulhofer 1998). More recently, MacKinnon has argued for a definition (to be used in domestic jurisdictions) which outlines a number of ways of understanding coercive circumstances and then states, "where any of this is done, consent shall be irrelevant." These would include: physical invasion of a sexual nature under circumstance of threat or use of force, fraud, coercion, abduction, or the abuse of power, trust, or a position of dependency or vulnerability, age, mental and physical disability, and other inequalities including 
drunkenness, and unconsciousness. In the prosecution of such cases an active exploitation of the inequality would need to be evidenced — not just the fact of it (MacKinnon 2014).

In sum, the legal community has wrestled with articulating and defining a concept of rape as crime and wrongdoing which reflects the category of experiences women have with sex that has violated sexual autonomy — an autonomy which to greater or lesser extents may resonate with societal mores or with individual experiences. In legal discourse, there has been a vacillation between and debate about how much this category should be defined from the subjectivity of the individual, that is, around consent and the violation of an individual woman, and how much it should be defined by external factors-force, a coercive environment, power dynamics, or as a crime against a larger community—even humanity. Whenever law is constructed or applied it invites us to rethink what rape is. As we have seen, the law, particularly as it has developed in the context of war, wrestles with the individual and relational dimensions of the transgression of rape which animate the central question of what rape is.

\section{Socio-cultural norms and transgressions}

What about when the experience of being forced to have sex occurs and there is no (strong) relationship to an external rule such as the laws discussed in the previous section? That is, in some situations there may be no (or a weak) concept of rape as a legal construct, but is there still an experience of it?

On multiple occasions over the years when I have discussed research with Acholi interlocutors they say that, "rape never used to be there," suggesting it is a "new" concept. A 
particular notion of rape as a reportable crime, in which the state might intervene, and perhaps should, has grown in prominence during the war and with an influx of NGOs, radio talk shows on gender-based violence and women's rights advocacy campaigns. This concept of rape is based on an idea of sexual autonomy and women's rights to make choices about their own bodies which is less evident in earlier notions. An example is the reaction of one of the eldest women I interviewed. She did not know her age but made references to colonial legislation around the time she was married that would indicate she must have been around a century old. She laughed at my questions and said they were "very useless," because, as she expressed, "it is hard to even say whether a man forced you to have sex when you never even thought that refusing was an option and you were never asked if you agreed." Another elderly woman also laughed and had the same opinion of my queries being "very useless." Her explanation was that she and her age mates did not know what "rape" was in those days, although, she added, of course, men used to force them. If we are socialized not to think of ourselves as sexually autonomous, trained by life to suppress sexual desires and aversions, as some of these elderly informants seem to have been, at first blush this would seem to negate an experience of rape. It is, perhaps, indicative of what du Toit described as the ways patriarchal symbolic order crushes female subjectivity and political and sexual agency by denying the full subject status of women (du Toit 2009). Yet, there seems to be something more complicated represented in these women's stories. Immediately after making the point above, the woman goes on to say that men used to "force" them. In this case, she and her age mates had an experience of rape, but there was no language, or concept to attach it to - it was, "hard to say" as she put it. They were forced to have sex but "rape" was not there.

In other words, there was not a strong or direct relationship to an external norm which classified forceful sex as a moral, social, and/or legal transgression. There were, and are, 
other external rules which shape notions of transgressive sexuality. For the Acholi, the cik Acholi, or Acholi way/law, as it is often referred to, does not seem to resemble corpus juris. "Law," or the content of it, in this context might best be understood as the "norms about norms," as Gluckman similarly argues was the case among the Barotse (Gluckman 1973). The Acholi normative repertoire is referred to as cik but very few Acholi or Acholi scholars (with the exception of Ker Kal Kwaro Acholi, the Acholi association of customary leaders) would claim these bear analogy to legal codes and are more akin to ideas which act as a mode of social control (Malinowski, 1926). In this way of thinking, consent, is not the paramount consideration in sexual ethics (Porter, 2015a). I have discussed consent and coercive environments in the previous section as central to the understanding of criminal versus legal sex. In terms of social understandings in the Acholi, however, consent is secondary and not a pivotal factor in distinguishing acceptable sex from sexual transgression. The defining features of sexual transgressions are how sexual acts either contribute to or undermine social harmony and contribute to the project of making a "home." Commonly, this has to do with whether customary payments between groups of relatives have occurred, the reproductive potential of the act, and observation of other social and cosmological mores which convey respect for social ordering such as observing the rules of exogamy, proper times and places for privacy, and sleeping with someone in the same age group. These understandings of sexual mores reflect an understanding of "being" as relational—and the relations in question as profoundly patriarchal. Many of these features are not unique to the Acholi. Ideas of sexual transgression, which as Das phrased it, is understood as dismantling, "the orderly exchange of women" (Das 2007: 21) is remedied by the rightful reinstatement of "proper" kinship: women under fathers and husbands, or as Lévi-Strauss termed it the "reinstatement of correct matrimonial dialogue of men" (Lévi-Strauss 1969: 30-33, 231). Rape which does not disturb the orderly exchange of women or the matrimonial dialogue of men might then be 
experienced as an individual transgression but not have a strong link to a concept in either social understandings of wrongdoing or in legal precepts.

Many Acholi women talk about being forced to have sex as something "normal" or gin matime (literally, "something that happens"); they equally talk about it as something that is "not good," "bad," and as having negative impact on their relationships, mental health and bodies. The relationships women have with external rules and the concept of "rape" are on shifting existential ground in that they are always and ever evolving. Even though virtually none of the women I have encountered in my research actually accessed legal avenues of redress, the way that they discuss their experiences (particularly marital rape) indicate that laws about rape are (for some) increasingly part of what shapes their notions of appropriate sexual behavior. The idea of sexual violence appears to be evolving from only possible social wrongdoing if it transgresses the norms noted above, to a crime that also abuses the rights of an individual that should be protected by the state. For instance, some of my younger informants said that if forced to have sex by someone they were courting but had not yet chosen to sleep with they could "sack him" or fight back, responses which would likely not have occurred to the elderly informants quoted above in their youth. Many of the women I spoke to that experienced sexual violence in their marriages, however, or at the beginning of their relationships to their husbands did not classify his actions as "wrong" and, indeed, knew that if the matter were raised among their relatives or their community, they themselves would be blamed (Porter 2015b). There is a tendency in much feminist activism and scholarship to write of women as wholly constituted by and yet somehow separate from the power structures which impose their inferiority. As Cahill points out, "such a model ignores the possibility of resistance as well as the degree to which women themselves are implicated in that structure" (Cahill 2001: 4). Patriarchy, of course, holds enormous sway over the lives 
of women, but as Cahill reminds us, its power is neither unidirectional nor omnipotent. To the extent that women are implicated, it is neither to say that they are not harmed by it nor to say that they are never critical of it, but women inhabit patriarchy. If we are to understand a woman's ontology as relational, this means seeing her as part of and constituted by her social being/existence. Such relational ontologies of personhood are not unique to the Acholi. It finds resonance on both the wider continent (Comaroff and Comaroff 2001) and beyond (see for instance Abu-Lughod 2002; Mahmood 2005). But there are limits to this understanding, and the reactions of women in such circumstances call our attention to these.

It would seem that whether or not one thinks of an action against one's body as being a crime or not, a socially patterned sexual transgression or not, even where the concept of rape is absent from cultural and legal repertoires, there is an experience of it which is aggrieving. As in the Acholi idiom, women who had been forced to have sex say that they had a "leaky heart." We might say that there are pained bodies without "rape."

\section{An internal threshold? Bodily invasion}

If, as seen in the previous sections, even in the absence of a legal concept of rape, and effectively socially condoned violence, women still experience forced sex as an internal transgression which they were aggrieved by, then the phenomenon of "rape", must be something more than just a socio-legal construct. Within anthropology, the "universality of the autonomous person" is regularly interrogated in light of cultural and historical specificity (Comaroff and Comaroff 2001; La Fontaine 1985). "The autonomous person," Comaroff and Comaroff argue is an imaginaire, an "ensemble of signs and values, a hegemonic formation," 
but it does not "exist as an unmediated sociological reality" (Comaroff and Comaroff 1991). While I would endorse the premise of an imaginaire, which is undoubtedly variant across space and time, implicitly, this suggests that there is something in existence to be mediated sociologically — something which transcends the particulars of culture or national and international legislations. Limited as I am by both, tentatively, I began to wonder if rape is a story of the harm and badness of individual bodily invasion. Thus a threshold for sexual transgression would be (at least partially) corporeal and internal. In this case, even in contexts where ideas of individual consent do not define the public ethics of sexuality - there is an idea that individual choice matters and that having one's body overpowered is aggrieving. ${ }^{\text {viii }}$

Although ideas of abhorrent sexuality, and what constitutes sexual transgression that end up shaping the external rules which govern it may overlap with the protection of sexual autonomy, often they do not. Sometimes, they instantiate other social values/forces which directly and indirectly undermine it. Within anthropology, ontological reflections on the composition of human beings have argued that (at least in certain contexts) persons-single actors - are not thought of as individuals, that is indivisible, bounded units. Instead, persons are thought to be dividual, or divisible. In the northern Ugandan context, Baines writes of the relationality of Acholi understandings of personhood (Baines 2017). Such insight resonates, to some extent, with my observations of Acholi life where I have argued that we cannot conceive of intimate relations, sexuality, or sexual violence if we view individuals apart from the social and cultural worlds they inhabit. As one of my informants summed it up poignantly, "You cannot understand Acholi love if you think that it is between two people." The same can be said of sexual encounters, whether characterized by awful excesses of violence and force or mutual intense desire, passion, and enjoyment. Despite this, the continued experience of forced sex as aggrieving even when violence is routinized and 
socially condoned suggests a possible limit to how "dividual" individuals are. It suggests that we exist not only as entangled, mutually constituted beings. We are also bounded.

One of the ways that human beings might be understood as "bounded" is with skin.

Even physical bodies, we are told, are made up of permeable boundaries. Much of the anthropological writing which supports a notion of dividuals is strongly material, pointing to the ways that bodies themselves are literally composed of bits of other persons transacted in relation with other persons - one thinks of breast milk, blood, semen, shared meals, and the like (Carsten 1995; Strathern 1990, 2004). In this line of thinking, to exist, dividual persons absorb heterogeneous material influences (Marriott 1976). Rape then might be understood as a transgression of a corporeal threshold, or to use the oft-cited words of Mary Douglas, as "matter out of place" (Douglas 1966).

Here Csordas" notion of "somatic modes of attention" seems relevant. He writes that "embodiment as a paradigm or methodological orientation requires that the body be understood as the existential ground of culture." He distinguishes the body as a biological, material entity from embodiment which can be understood as an "indeterminate methodological field defined by perceptual experience." Csordas suggests that we "take the 'lived body' as a methodological starting point” for analysing human participation in a cultural world (Csordas 1993). Approaching cultural phenomena from the standpoint of embodiment does not mean to suggest that the body is pre-objective. Indeed, biology and culture are co-produced and there is no presocial body—including genitalia-with the inherent capacity to rape or be raped (Helliwell 2000; Lock 1995). Bodies and our attention to them are always already embedded in a cultural world. Thus we might accept Merleau- 
Ponty's (1962) principle of indeterminacy of perception as an inevitable background condition of our analyses on any phenomena - including the question of rape.

In relation to feminist theories of the body, much attention centers around the relationship between gender and sex, the elasticity of categories and the significance of sexual difference. For our purposes here, it is worth noting that the insights of prominent scholars, Elizabeth Grosz, Rosi Braidotti, Mora Gatens, Judith Butler, and Luce Irigaray, all differ in significant ways but they share an understanding of the feminist subject as material and embodied and an understanding of embodiment as central to agency. Importantly, it is primarily through embodiment that people become sexed. In Cahill's articulation of her embodied theory of rape she finds fault in feminist schools of thought on rape based on misunderstandings of the relations between power and the body. In one strand of thinking, Cahill critiques the "rape is violence not sex" paradigm exemplified by Brownmiller's work, as based on an idea of sex as natural, the body as wholly biological. The assumption of sexuality as a biological matter presents a somewhat familiar but misleading dichotome between nature and culture. The other strand of thinking, which she associates with MacKinnon's position, sees the body as wholly or solely constructed and thus under totalizing patriarchal power. Cahill instead suggests we "understand the body as a central site for both the production of power and the possibility of resistance," where women's agency becomes possible (Cahill 2001: 4). Ultimately, she tells us, personhood is constructed in relation to embodiment and sexual difference. Bodily integrity then, is necessary to the constitution of a subject and rape is a threat to this.

In my book, (Porter 2017), I draw on the idea of an internal threshold, one that, I reasoned, is perhaps written on the body-something corporeal in a material sense $\mathrm{e}^{\mathrm{ix}}$. And then, in the 
footsteps of many anthropologists, in fieldwork, where we are confronted with a new ethnographic situation that challenges our previously held understandings — and indeed sometimes reality itself, something happened which forced me to reimagine rape.

\section{Non-corporeal rape}

An Acholi friend told me a story. We will call her Olivia. We were discussing her preparation for expected visitors and I was asking rather quotidian questions about where they were from, how she knew them, and the plans for their stay when she made a rather startling disclosure: "I was raped and married by a spirit," she said. A few months earlier, a dark figure of a man entered her room as she lay on her bed, she recounted. He was strong and despite her struggle overpowered her quickly and violently forced her to have sex. She was unable to speak or shout while it was happening but as soon as he had finished and released her she questioned the specter as to why it had done this. He told her that it had been sent. It was not his own will, nor did he have any personal ill intentions toward her-it was just a job to him and one that he had been paid very well for-so he did it. She should not take it personally.

She was clearly distressed and deeply frightened, by both the experience of the ghostly rape itself as well as the question of who had paid the spirit and what effect it might have on her life. Not long after this first encounter, she had a dream where a friend (from waking life) was beckoning her to hurry because her wedding was about to start. She was confused and asked the friend who the groom was and how it was possible that she was getting married without prior knowledge of the occasion. Eventually, she was led to a large square room with no one inside that she could see though there were military fatigues hanging on the walls. She felt uneasy about entering. As soon as she did an invisible arm held her by the shoulders and 
a ring was placed on her finger. Feeling the event unholy, as is her habit, she prayed and repeated "Jesus." This, she said, diminished the power of the arms which restrained her and allowed her to escape. As we sat and discussed these occurrences she explained that they were connected and that she was being bound to the spirit that had raped her with the intention that the spirit-husband would spoil all chances of love or happiness with a fleshand-blood man. She recounted her thought process in the course of the dream, how she felt she did not deserve the terrible wedding, that she had taken pains in life not to entangle herself with the demonic world. She had never turned to witchcraft to solve her problems though they were many. It was an injustice, that she should be bound to a dark spirit in marriage. Toward the end of the dream, she described how she prayed and felt guided to remove the ring from her finger and throw it in a particular location, which she did. After she woke up she wanted to take steps to minimize the harm of this ghostly rape and marriage and the ill-intentions of whomever had sent it. It had been a rather consuming pursuit over the months prior to our dinner. The visitors who were coming were a prayer team with a reputation for successful spiritual interventions in such cases. Our conversation was unsettling, and ultimately decentering.

Although sexual violence has been a long-standing focal point of my research, rape by a spirit was something I had yet to encounter. However, as I soon discovered it is a pervasive phenomenon - ghost rape is everywhere and has been for a long time. Recall the biblical passage where "Nephilim" or demons have sex with women (Genesis 6:4). Demonic rape is depicted in great European art. Henry Fuseli's 1781 startling painting The Nightmare is exemplary. It depicts a woman as she dreams, as well as the content of her nightmare- $-\mathrm{a}$ lascivious demon on her body, something that commentators have noted would have been familiar in Germanic folklore at the time (Russo 1990). Although social interpretations of 
such experiences manifestly vary, the idea that a demon or non-corporeal being might have a sexual relationship with a human, even a forced one, appears common cross-culturally and diachronically. Physically experienced demonic pressure is even part of the etymology of "nightmare.” Through history such "erotic nightmares" have haunted everything from medieval folktales, mythology, gothic fiction, to American pop culture (Stewart 2002). One thinks of the film Ghost or Ira Levin's novel Rosemary's Baby (and its adaptation for the screen), or the Californian rock band Incubus named after the medieval legend, and the host of websites for those with ghost fetishes. In this section, I aim to explore the implications of ghostly rape in Acholi culture in more depth and bring these experiences into our conversation of what rape is, which until now has been focused around socio-legal notions and the body.

After this first interaction, I asked another woman who we will call Immaculate, about what happened to Olivia and whether she had ever heard of something like that before. She said it was very common and that it happened to a teenage mutual acquaintance of ours "Grace." With Grace, she said, a dark figure of a man would come when she was in bed and stand in the doorway. When it came nearer to her it would change into the shape of a frog and then rape her while choking her. I asked how a frog rapes a woman (gesturing toward critical parts of human anatomy) and she just laughed at me and said, "It happens! It's like a frog but not actually a frog." Her articulation seems to suggest that it does not have the physical body of a frog, but that in the absence of genitalia capable of raping, rape still "happens." Then she told me that a similar thing had happened to her. She had had a recurring dream that a white man who spoke Acholi perfectly and had a lot of hair would come and sleep with her. Because she phrased it as "sleeping with" her, I asked whether it was "forceful" or "in the way of negotiation" (a typical way of discussing agreeable sex). She paused, so I apologized if my 
question seemed too personal and emphasized that she did not need to answer, but did she enjoy it? Was it something she had wanted to do? She emphatically responded that she did not like it at all and that he would hold her down while she was fighting him in the dream until he overpowered her. The dream recurred regularly for about a year until after one of these forced encounters the dream changed and she was in a dark room filled with people whose faces she could not see and the white apparition put a ring on her finger and "married" her. I asked if it was nyom Acholi, a customary marriage where exchanges would have occurred. She said that none of her relatives were there and there were no payments, and so it was not like nyom Acholi. She said it was more like a church wedding, a nyom maleng, literally "holy wedding" with a ring, binding her to him, but rather than being holy it was evil and they were not in a church. There was no pastor. In the years which followed, up to the time she shared this story, she had suffered the death of four children before they reached their first birthdays, and subsequent infertility. She had also had multiple failures in her love life, including being separated by relatives from the "love of her life" whom she had lived with for two years when it was discovered that they were distantly related. She understood this considerable pain as emanating from the ghostly rape. As I began to ask more Acholi interlocutors about such instances it became clear that spiritual rape was far from unusual. Most people had knowledge of such occurrences if not personal experiences with them.

These occurrences were experienced as quite grave. There is a temptation to rush to explanations, diagnoses which medicalize, pathologize or offer ready functional interpretations of happenings which seem otherwise incomprehensible. I take a basic phenomenological approach to the problems experienced by my informants inasmuch as I am less concerned with the empirical status of spirits that torment them than the lived experiences of those who are affected by them. With what some have discussed as a kind of 
“methodological agnosticism” (Engelke 2002: 3; O’Byrne 2017: 87, 38, Poloma 2001: 173), my aim is to attend to how these spirits effect the lived realities of these women and what this means in terms of understanding rape.

Without a background in mental health, even if I wanted to, it would of course be difficult to offer any expert opinion on the psychological "causes" of such encounters. I asked a psychologist friend, also working in Gulu with people affected by the war, for her interpretation and her first thought was psychosis. Another mental health professional suggested a possible childhood trauma (indeed in the case of Grace I am aware of her having experienced such) or perhaps an amplification of subconscious fears, assimilated from their surroundings. It would certainly make sense that a high exposure to societal violence and to sexual violence in particular during waking life could lend themselves to dreams composed of the same themes. In a context where I have found about 40 percent of women over sixteen having been raped (Porter 2012) it is perhaps not surprising that ghostly rape would feature prominently in the subconscious substance of dreams.

But we may gain more insight if we avoid the temptation to necessarily equate social and spiritual torment with individualized medical pathology, and instead pause longer and consider: if the concept of rape was assigned by these women to their experience which was immaterial and not corporeal—what does this mean for how we understand the thing we call rape?

Both women experienced and reacted to their ghostly rapes and forced marriages as urgent and very serious incidences of violation entailing grave consequences if left unaddressed. With my particular socio-cultural orientation toward dreams I imagine I would, like them, be 
frightened by such a nightmare. However, once awake and upon realization that it was a dream and "not real"- - the fear would subside. I would not expect the nightmare to negatively affect my life, nor would I think it was an indication of the existence of malevolent forces determined to cause me harm. Yet both women talked about what happened without distinction between waking life and dream in terms of "what actually happened." These events constituted part of "the real." Jackson talks about "the real" as connections between human life and the earth, to generations over time, to multiple geographies and cultures - the real is essentially about "relatedness." Intersubjective life is constituted by not only human relationships but also abstract ideas, imaginary beings, inert object, etc. (Jackson 2009: 2).

For Olivia and Immaculate, spiritual rape and marriage were not representational — that is they did not experience it as either an expression of their subconscious fears/desires or prophetic — being generated externally. They experienced these phenomena as real occurrences instigated by people they knew and with tangible negative consequences for their lives and well-being - much like rape with bodies. Jackson writes of situations he refers to as "limit" situations, as moments where we come up against the boundedness of being. Sexual encounters seem to be among the most powerful. He writes, how "natural it seems to understand this [limit] experience in sexual terms, since it is in making love that our ordinary sense of boundedness and being is overwhelmed and momentarily lost before we return to ourselves once more, renewed" (Jackson 2009: 158). If we extend this observation of "making love" to other sexual encounters, we might replace the "making love" with "rape" and renewed with something much less pleasant but equally powerful in terms of overwhelming boundedness. For Immaculate and Olivia these spirit rapes overwhelmed the boundedness of their being. 
When we take seriously the lived reality of non-corporeal rape it points us to a concept of rape which happens to the whole person. Cahill has written that "subjects do not have bodies; subjects are bodies" (2001: 13). But the experiences reflected on here suggest we take a view that includes but is not limited to bodies_-but beings.

\section{Conclusion: Reimagining rape as sexual transgression on being}

To the extent that one deals with a topic such as rape, it is, by default, a normative stance. Rape is bad. But what is it that we are actually talking about? The idea that notions of abhorrent sexual behavior are universally shared would be wrongheaded to say the least. Even the most cursory reading of literature on global sexualities confirms this, as does the discussion of Acholi socio-cultural notions above.

Donna Haraway queries what happens when, "bounded individualism has become unthinkable in the best sciences, whether natural or social. Seriously unthinkable: not available to think with" (Haraway 2006). As we have discussed, it is essential to acknowledge how we are mutually constituted. Any act is not just between two people. Agency is always entangled and qualified. So, if we cannot assume the universality (or even particularity) of the bounded, autonomous individual what should the litmus test be for determining whether sex is wrongdoing or is acceptable?

In responding to my book (largely about rape), Adam Branch reflected that:

"Rape is where our desire to go beyond the bounded purposive, rational individual, the Western masculine human, runs aground; rape is where suddenly our well-intentioned 
embrace of entanglement, mutually-constituted selves, relationality, context, community, all of this suddenly hits a limit. When it comes to rape, the idea of "I am because you are," the idea of asking people to understand themselves as constituted through others, can sound like a cynical excuse for patriarchy and impunity for systematic sexual violence against women. With rape, we suddenly want to bring back the idea of the autonomous, bounded individual with rights that can be violated by others, and to condemn rape because it is a violation of that moral individual" (Public event, March 14, 2017).

The experiences reflected upon in this article suggest that human beings are necessarily both individual and dividual.

What I want to suggest here is that rape is a sexual transgression of being. This means that it is existential - in that it is lived - it is a transgression of our being in the world. It is not fixed, it is and it is always just becoming. And it is phenomenological. As discussed above, there are legally and socially constructed concepts which are made manifest through experience and conversely are constructed with reference to those experiences. The experiences of Acholi women considered here suggest that we are not just corporeal beings written upon by the social body, nor solely relational beings. Aspects of our being are immaterial, symbolic, conscious and subconscious. In essence, this understanding is about "being" and all that that entails. Imagining rape in reference to being allows for a decentering indeterminacy to what that means-overcoming dualities between relational and bounded ontologies, the material and immaterial. In terms of methodology, it suggests a starting point which includes but goes beyond the somatic. In the Acholi, as elsewhere, the idea of being is as social and cosmological as it is material and thus the experiences described above of sexual violence at the hands of spirits, and the social and cultural norms on sexual transgression are legible. The law has less but still some sway over the norms that govern human sexuality—perhaps 
increasingly so. But our imaginings of being in-the-world - in the Acholi, as elsewhere - are not just social and cosmological even in the most collective of societies where interdependence and entanglements are pervasive, recognized, and celebrated.

This article has explored where the threshold of sexual transgression originates. Is it simple physical biology and inalienable and/or also constructed? Does it come from a deeply embodied sense of being violated or a normative limit that is also a social construct? The women who described the rather quotidian experience of being forced to have sex, where rape never ceased to be experienced as violation, described being forced to have sex as something which "happens" (time,) implying a level of normalcy. Such experiences suggest the limits of routinization of violation to define the threshold. They can affect the social and structural ways violence is experienced, but somewhere, on the body, I had reasoned, there is a threshold and perhaps universal story of the idea of being forced.

The experiences of non-corporeal rape challenged the idea that the threshold exists solely on the body. After years of working on this, my own feeling is that the threshold is existential and phenomenological. That is, the source of violation is a deeply existential one. It cannot be reduced to any one thing, socially patterned, or universally shared sense of physical biological violation. I now want to suggest that rather than a "biological violation" it would be better to say rape is a shared sense of a sexual trespass on the boundaries of being. The stories of non-corporeal rape reminded me to take seriously Acholi notions of "good existence," which are deeply social and cosmological, as well as individual, and so it is little wonder that rape could also be experienced in each of these ways as a violation of "being." 
In using the concept "rape" there are a variety of things one may be interested in doingquantifying the scope and scale of sexual violence, knowing the prevalence, prosecuting, repairing — or something else. I am suggesting here a way of re-imagining rape and not necessarily advocating for specific changes in legal (or methodological) definitions. It is not at all clear, for instance, that bringing spectral rape into legal definitions would be desirable - almost certainly it would not be. However, in noting the ways that different aspects of being come together to constitute the experience of rape we may perhaps move toward a fuller imagining of what it $i s$ - and therefore fashion a concept of it that better reflects the human experience and not just the western feminist experience.

\section{REFERENCES}

Abu-Lughod, Lila. 2002. Do muslim women really need saving? Anthropological reflections on cultural relativism and its others. American Anthropologist. 104 (3): 783-790.

Baines, Erin. 2017. Buried in the Heart: Women, Complex Victimhood and the War in Northern Uganda. Cambridge: Cambridge University Press.

Bedont. Gender-Specific Provisions in the Statute of the International Criminal Court, in Essays on the Rome Statute of the International Criminal Court.

Boesten, Jelke. 2014. Sexual violence during war and peace: Gender, power and post conflict justice in Peru. Macmillan.

Carsten, Janet. The Substance of Kinship and the Heat of the Hearth: Feeding, Personhood, and Relatedness among Malays in Pulua Langkwai. American Ethnologist. 22(2): 223-241.

Charlesworth, Hilary. 1999. Feminist Methods in International Law, 93 AM. Journal of International Law. 379-386

Charlesworth, Hilary and Christine Chinkin. 2000. The boundaries of international law: A Feminist Analysis. 315-21.

Chinkin, Christine. 1994. Rape and sexual abuse of women in international law. European Journal of International Law. 5: 326-341.

Comaroff, John and Jean Comaroff. 2001. On Personhood: An Anthropological Perspective from Africa. Social Identities 7 (2): 267-283.

Comaroff, John and Jean Comaroff. 1991. Of Revelation and Revolution, Volume II, The Dialectics of Modernity on A South African Frontier. Chicago: University of Chicago Press. 
Copelon, Rhonda. 1994. Surfacing Gender: Reconceptualizing Crimes Against Women in Times of War, in Mass Rape: The War Against Women in Bosnia-Herzegovina editors, Alexandra Stiglmayer, ed., Mario Faber trans. 197-218.

Crazzolara, J. Pasquale. 1938. A study of the Acooli language: Grammar and vocabulary. London: Oxford University Press.

Csordas, Thomas. 1993. Somatic Modes of Attention. Cultural Anthropology. 8(2): 135-156

Das, Veena. 2007. Life and words: Violence and the descent into the ordinary. Berkeley, Los Angeles and London: University of California Press.

Douglas, Mary. 1966 [2002]. Purity and Danger: An Analysis of Concept of Pollution and Taboo. London and New York: Routledge.

du Toit, Louise. 2009. A Philisophical Investigation of Rape - The Making and Unmaking of the Feminine Self. New York: Routledge.

Engelke, Matthew. 2002. The Problem of Belief: Evans-Pritchard and Victor Turner on the 'inner life'. Anthropology Today 18 6):3-8.

Gluckman, Max. 1969. Concepts in the comparative study of tribal law. In Law in culture and society, edited by Laura Näder. Berkeley: University of California Press.

Goldstone, Richard J. 2002. Prosecuting rape as a war crime. Case Western Reserve Journal of International Law. 34: 277-95.

Halley, Janet. 2008a. Rape at Rome: Feminist Interventions in the Criminalization of SexRelated Violence in Positive International Criminal Law. Michigan Journal of International Law. 30 (1): 3-123.

Halley, Janet. 2008b. Rape in Berlin: Reconsidering the Criminalisation of Rape in the International Law of Armed Conflict. Melbourne Journal of International Law. 9 (1): 78-124

Hawkesworth, Mary E. 1989. Knowers, knowing, known: Feminist theory and claims of truth. Signs. 14(3): 533-557.

Helliwell, Christine. 2000. "It's Only a Penis": Rape, Feminism, and Difference.” Signs. 25 (3): 788-816.

Henry, Nicola. 2014. The Fixation on Wartime Rape: Feminist Critique and International Criminal Law. Social \& Legal Studies. 23 (1): 93-11.

Jackson, Michael. 2009. The Palm at the End of the Mind: Relatedness, religiosity, and the real. Durham and London: Duke University Press.

La Fontaine, J.S. 1985. "Person and Individual: Some Anthropological Reflections," in M.

Carrithers, S. Collins and S. Lukes (eds) the Category of the Person: Anthropology,

Philosophy, History, Cambridge: Cambridge University Press.

Lehr-Lehnardt, Rana. 2002. One Small Step for Women: Female-Friendly Provisions in the Rome Statute of the International Criminal Court. 16 BYUJ PUB. L. 317, 339

Lévi-Strauss, Claude. 1969. The elementary structures of kinship. Translated by James Bell, John Von Sturmer, and Rodney Needham. 1949. Reprint, Boston: Beacon Press.

MacKinnon, Catharine. 1994. Rape, genocide, and women's human rights. Harvard women's law journal. 17 (5): 5-16.

MacKinnon, Catharine. 2005. Defining Rape Internationally: A Comment on Akayesu.

Columbia Journal of Transnational Law. 44 (1): 940-958. 
MacKinnon, Catharine. 2014. Public Lecture

https://www.youtube.com/watch?v=Rrijeaqc04A Nordiskt Forum.

Mahmood, Saba. 2005. The politics of piety: The Islamic revival and the feminist subject. Princeton, N.J.: Princeton University Press.

Malinowski, Bronislaw. 1926. Crime and custom in savage society. London: Rowman \& Littlefield Publishers, Inc.

Marriott, McKim. 1976. Hindu Transactions: Diversity without Dualism, in B. Kapferer, ed. Transaction and Meaning. Philadelphia: ISHI Publications.

Metcalf, Thomas. 2007. Imperial Connections: India in the Indian Ocean Arena, 1860-1920.

Merleau-Ponty, Maurice. 1962. Phenomenology of Perception. Translation C. smith. London: Routledge.

Moffett, Helen. 2006. "These women, they force us to rape them:" Rape as narrative of social control in post-Apartheid South Africa. Journal of Southern African Studies. 32 (1): 129-144.

Moon, Claire. 2006. Narrating political reconciliation: South Africa's Truth and Reconciliation Commission. Lanham: Lexington Books.

Munro, Vanessa. 2010. From Consent to Coercion: Evaluating International and Domestic Frameworks for the Criminalization of Rape, in Munro and McGlynn, eds. Rethinking Rape Law: International and Comparative Perspectives.

Nordstrom, Carolyn. 2005. (Gendered) War. Studies in Conflict and Terrorism. 28 (5): 399411.

O’Byrne, Ryan. 2016. Becoming Christian: Personhood and Moral Cosmology in Acholi South Sudan. Doctoral thesis, University College London.

Poloma, Margaret M. 2001. The Millenarianism of the Pentecostal Movement. In Christian Millenarianism: From the Early Church to Waco, S. Hunt, ed. Indianapolis, IN: Indiana University Press. 166-186.

Prum, Richard O. 2017. "Duck Sex and the Patriarchy," The New Yorker. May 17, 2017.

Prum, Richard O. 2017. The Evolution of Beauty: How Darwin's Forgotten Theory of Mate Choice Shapes the Animal World - and Us. New York: Doubleday Books.

Schulhofer, Stephen J. 1998. Unwanted Sex: The Culture of Intimidation and the Failure of Law. Cambridge, MA: Harvard University Press.

Strathern, Marilyn. 2004. Partial Connections. Walnut Creek, Lanham, New York, Toronto, Oxford: Rowman \& Littlefield Publishers, Inc.

Sylvester, Christine. 2013. War as Experience: Contributions from International Relations and Feminist Analysis. New York and London: Routledge.

Strathern, Marilyn. 1990. The Gender of the Gift: Problems with Women and Problems with Society in Melanesia. Berkeley: University of California Press. 


\section{NOTES}

${ }^{\mathrm{i}}$ It is important to note that most of my research has been conducted in an extremely heteronormative context and has largely focused on sexual violence perpetrated by men against women and girls. I therefore will often use the gendered language which reflects my material. However, it seems likely that the analysis may have broader resonances with male or other genders' experience of sexual violence as well.

ii Exemplified in much of Catherine MacKinnon's work and critiqued as overly totalizing by Cahill (2001).

iii Although this was clearly not always the case as the noted language in the Geneva Conventions shows.

iv It is interesting to note the history of how the penal code came into effect. It was a version of codified English case law of the late $19^{\text {th }}$ century that migrated from India, to the Strait Settlements before making its way to Uganda and East Africa (see Metcalf 2007, in particular chapter one "Governing Colonial Peoples" pp 16-45). This may help explain why, for instance, false representation and impersonating the victim's husband is given prominence as it reflects case law in England from the time.

${ }^{v}$ This paragraph also draws on information presented by Nantudde Lwanga, Assistant Director of Public Prosecutions, Justice Law and Order Sector Regional Workshop in a 2009 paper entitled "Investigation and Prosecution of Sexual Offences."

${ }^{v i}$ A proposed Sexual Offences Amendment Bill, which had not been passed into law at the time of writing, might address some of these issues.

vii Although Helliwell's work amongst the Dayak community of Gerai in Indonesian Borneo reminds us that this is not everywhere the same, and thus neither 'natural' nor inevitably so (2000).

viii The idea that sexual choice matters extends beyond the social worlds of humans. Scientists have long noted this as an aspect of evolutionary biology. Plum, for instance, notes in a study on duck sex that the female duck's genitalia has evolved to frustrate forced intercourse and to lower the likelihood of her being fertilized against her will. As Plum writes, "freedom of choice matters to animals, even if they lack the capacity to conceptualize it." (Plum 2017, emphasis mine).

ix Unless stated otherwise, my use of "the body" mostly refers to the individual body and not to the other "two bodies": the social body, or the body politic as analytic domains. (ScheperHughes and Lock 1987; Douglas 1973) 